\title{
Drug Defaulting in a General Practice*
}

\author{
A. M. W. PORTER, $†$ M.D., D.OBST.R.C.O.G.
}

\begin{abstract}
Summary : Different groups of patients in a general $\checkmark$ practice have been under close observation by defined methods to assess the extent of their adherence to drug schedules. Patients taking antibiotics, admitted to a short drug trial and prescribed long-term treatments, proved in most cases to be compliant. Antenatal patients taking a once-daily dosage of prophylactic iron were more co-operative than those taking divided dosages. Socially isolated patients and those of low social class were particularly likely to neglect their drugs.

It is suggested that the significance and extent of the problem have been largely ignored and that all drug trials undertaken on outpatients should incorporate methods of detecting defaulters.
\end{abstract}

\section{Introduction}

Both clinical experience and published reports suggest that unsupervised patients often fail to take the tablets prescribed for them. Knowledge of the extent of patients' failure to co-operate is important not only for the effective treatment of the individual but also in order to assess the efficacy of the drugs given. Failure to comply with instructions may explain some of the paradoxical situations encountered, such as conflicting evidence from clinical trials, the contrast between invitro and in-vivo effects of antibiotics, and unexpected therapeutic failures. Examples of defaulting may be found in reports on the prophylaxis and treatment of malaria, anaemia, rheumatic fever, tuberculosis, and other disorders (Porter, 1967).

Three articles from the United States have testified to the alarming extent geriatric patients fail to understand and observe instructions (Curtis, 1961; Schwartz et al., 1962; Schwartz, 1965). A detailed study of the incidence of medication errors of American outpatients was published in 1966 by Malahy ; the rate was found to be high and polypharmacy was indicted as a cause.

Joyce (1961, 1962), using a tablet marker (phenol red) and a method of tablet counting, concluded that only about half of his outpatients with rheumatoid arthritis observed instructions. A similar proportion of defaulters was found by other workers using for the most part methods of tablet counting (Park and Lipman, 1964 ; Lipman et al., 1965).

Parkes et al. (1962) followed up 100 schizophrenic patients after their discharge from hospital. They concluded that almost half of the courses of drugs prescribed were probably not taken as intended by the doctor, a figure which was confirmed in a similar study by Renton et al. (1963). Schizophrenia may constitute a particular problem (Ellison, 1964); the percentage reduction of tuberculosis among patients on isoniazid was found to be much less for schizophrenic outpatients than for others (Ferebee, 1964).

Willcox et al. (1965) reporting a study on psychiatric outpatients, in which both colorimetric and chromatographic methods of testing for drug metabolites in the urine were used, recorded a failure rate of $48 \%$ in 125 patients. Nevertheless,

\footnotetext{
* This paper is derived from a thesis submitted to the University of London for the degree of Doctor of Medicine. t General Practitioner, Camberley, Surrey.
}

they failed to elucidate the reasons for these lapses. Freis (1966) observed patients for a pretrial probationary period when only placebo tablets were issued, and concluded: "The pill count technique has been a revelation to us in disclosing the frequency with which patients neglect to take their medication regularly."

Evidence from the literature, though comprehensive, is somewhat fragmented and the few definitive studies deal with highly selected groups of patients. This paper reports the results of closely observing patients in a general practice over a period of three years. The practice is 30 miles $(48 \mathrm{~km}$.) from London and comprises a young new population grafted on to an established indigenous one and embracing a wide range of socio-economic groups.

\section{Method}

Three means of detecting tablet defaulters are available: interrogation; some method of residual tablet counting; and the discovery of a tablet metabolite or marker in the urine. In this study interrogation was rejected as being too subjective. A preliminary investigation was undertaken to assess riboflavine in the role of a tablet marker, and a means of measuring compliance by the number of residual tablets was also evolved.

\section{Tablet Markers}

A tablet marker that may be detected in the urine offers an important method of assessing the compliance of patients. The ideal marker should be non-toxic and there should be no evidence of teratogenicity. It must be pharmacologically and chemically inert and unlikely to react with other tablet constituents; its chemical composition should not be related to that of the drug it is marking. It should be unaffected by variations in the physical and chemical properties of the urine such as $p H$, temperature, and other urinary constituents. After ingestion it should be quickly and freely excreted in the urine and be non-cumulative. The urine concentration should reach a peak within a few hours of ingestion and be undetectable after about six hours. The method of detection should be simple, quick, and specific, but not too sensitive if false-positives are to be avoided. The chances of the marker appearing in appreciable quantities in the urine from dietary of self-medication sources should be slight.

The properties of the marker should be such that the patient is unaware, by colour or odour, of its presence in the urine; marking is an observational technique and not a disciplinary measure. It is undesirable that either by intent or by accident the patient should become aware that his habits are being observed.

Many possible choices exist, but in this study only two were seriously considered-fluorescein and riboflavine; the latter was favoured on ethical grounds, as it is a natural constituent of the diet.

\section{Riboflavine as a Marker}

Riboflavine accords well with the criteria of the ideal tablet marker, and it is readily and simply detected in the urine by 
fluorescence under ultraviolet light (Kuhn et al., 1933 ; Robinson, 1951).

It has one major disadvantage as a marker ; it has a structural similarity to the biogenic amines and phenothiazines (St. Bartholomew's Hospital Symposium, 1964). They may compete with each other at the enzyme level (Richter, 1961), and there is evidence that riboflavine affects the action of phenothiazines (D. Richter, personal communication, 1964).

Preliminary experiments were undertaken on myself to determine the best dose of riboflavine to be added to each tablet as a marker. A dose of $6 \mathrm{mg}$. was found to be reliable, particularly if early morning specimens were tested. Specimens with a specific gravity of less than 1005 were apt to produce false negatives and should always be discarded. The fluorescence obtained under an ultraviolet lamp clearly distinguished a specimen voided within a few hours of ingesting a marked tablet from control specimens; weak fluorescence was convincing evidence that the subject had not recently taken marked medication.

Reference to control solutions of fluorescein allowed any specimen to be classified into one of three grades in respect of fluorescence (Table I). All specimens were protected from direct sunlight and fluoresced within a few hours of voiding.

TABLE I.-Riboflavine in Urine, Classification of Degrees of Fluorescence

\begin{tabular}{|c|c|c|c|}
\hline $\begin{array}{c}\text { Strength } \\
\text { of } \\
\text { Fluorescence }\end{array}$ & $\begin{array}{c}\begin{array}{c}\text { Description } \\
\text { of }\end{array} \\
\text { Fluorescence }\end{array}$ & $\begin{array}{l}\text { Strength of Aqueous } \\
\text { Fluorescein Solutions } \\
\text { Producing Equivalent } \\
\text { Fluorescence } \\
\quad(\mu \mathrm{g} . / 100 \mathrm{ml} .)\end{array}$ & Comments \\
\hline $\begin{array}{ll}\text { Absent } & \ldots \\
\text { Weak } & \quad\end{array}$ & $\begin{array}{l}\text { Milky white } \\
\text { Faint yellow-green } \\
\text { tinge to milkiness }\end{array}$ & 二 & $\begin{array}{l}\text { Fluorescence of nor- } \\
\text { mal urine speci- } \\
\text { mens will serve to } \\
\text { demonstrate these }\end{array}$ \\
\hline Intermediate & $\begin{array}{l}\text { Definite yellow- } \\
\text { green glow }\end{array}$ & 50 & $\begin{array}{l}\text { Type of fluorescence } \\
\text { to be expected four } \\
\text { hours after inges- } \\
\text { tion of } 3 \mathrm{mg} \text {. of } \\
\text { riboflavine }\end{array}$ \\
\hline Strong & $\begin{array}{l}\text { Brilliant yellow- } \\
\text { green fluorescence }\end{array}$ & 250 & $\begin{array}{l}\text { Type of fluorescence } \\
\text { to be expected two } \\
\text { to three hours after } \\
\text { ingestion of } 6 \mathrm{mg} \text {. } \\
\text { of riboflavine }\end{array}$ \\
\hline
\end{tabular}

\section{Estimates of Residual Tablets}

Tablet counting may be of two kinds: the "discrepancy count" and the "discrepancy estimate." With the former method a known number of tablets are issued and the patient is requested to bring the box back at the next attendance; the residue is then counted and any discrepancy will be obvious. This method, which seems to have been used first by Corrigan and Strauss (1936), has the advantage that it is simple and objective. Unfortunately the possibility exists that the patient may either gain insight into the fact that he is under observation or even indulge in wilful deceit. The method lacks the necessary subtlety.

The "discrepancy estimate" method was developed for this investigation (Porter, 1966). A fixed and critical number of tablets are issued to the patient. At determined times he is seen again and there should, by design, be a small and known number of tablets left. The estimate hinges on the patient's reply to the challenge: "Do you need any more tablets, or have you enough left until I see you next time?" If necessary, discreet questioning will define a vague answer. The scheme is flexible, and by adjusting the number of tablets and the interval between consultations most treatment schedules and contingencies can be allowed for. Above all it ensures that patients are not aware that they are under close observation.

The group of patients in the trial reported below received exactly 65 tablets and were seen routinely at the end of the first, second, and third weeks. After admission to the trial they were started on one tablet three times a day. If at the end of the first week the response to treatment was indifferent the dose was increased to two tablets three times a day (" high schedule"); if the early response was promising the patient persisted with one tablet three times a day (low schedule). With the high schedule there should be two tablets left at the second consultation if the patient had been completely compliant, and with the "low schedule" the same number should remain at the third consultation. The selection of a threshold to distinguish the compliant from the non-compliant is entirely arbitrary. In the group of patients taking part in the trial (see below) a "compliance ratio" of 0.8 was selected as criticalthat is, 8 out of 10 tablets had to be taken to qualify as " compliant." Seventeen residual tablets may be equated with this threshold $(65-(80 / 100 \times 63)+2=17)$. If the relatively high qualifying ratio of 0.9 had been required then any patient admitting to more than 10 tablets $(65-(90 / 100 \times 63)+2=10)$ would have been classified as non-compliant.

\section{Estimation of Compliance of Long-term Patients}

The compliance of patients on long-term treatments can be readily assessed by determining the compliance ratio. This is defined as the number of tablets actually taken-as indicated by requests for prescriptions-divided by the number of tablets which should have been taken by a wholly compliant patient. The ratio will be below unity in a defaulting patient and more than unity if the patient exceeds the recommended dose. The reliability of the ratio as an index ultimately depends on accurate note-keeping, and it is possible to use it only where the structure of medical practice is such that one prescriber is the sole source of tablets. The ratio is independent of the duration of treatment and the daily dose schedule, and its accuracy will tend to increase the longer the period of observation.

\section{Results}

Four different groups were observed in the practice by one or more of the above methods.

\section{Clinical Trial}

A controlled trial of imipramine was undertaken over a twoyear period. Out of 93 patients presenting with sustained depression (14 men and 79 women), 11 were excluded in accordance with the trial protocol, leaving 82 to be admitted. The escape clause was invoked for one of these patients, and 19 failed to reattend at some stage, left the district, or admitted to failing to take their tablets (the overt defaulters). Data from a discrepancy estimate were available for 52 out of the remaining 62 patients $(84 \%)$ and data from urine testing for only $19(31 \%)$. This last figure is low owing to only half the tablets being marked and to other practical difficulties associated with the application of this method to a trial lasting only three weeks for each patient. No evidence of any sort was available about the compliance of five patients $(8 \%)$.

Of the 19 overt defaulters 14 were taking imipramine rather than the placebo ; this suggests that side-effects were a potent cause for absconding.

Three of the patients who completed the trial were judged non-compliant from urine testing alone, but all had satisfactory discrepancy estimates of more than 0.8. Two patients were judged non-compliant from the discrepancy estimate; there was a conflict of evidence from the two methods in one of these. These results do not provide evidence of widespread occult defaulting, and it would seem that most patients who completed the trial took their tablets as instructed. 


\section{Patients on Short-term Antibiotics}

Patients were admitted when administratively convenient and some selection may have inadvertently occurred. Fifty-four were observed. Children who were prescribed an antibiotic in the form of a syrup were not suitable for the series owing to the difficulties in estimating residual amounts of a liquid.

The 54 patients were made up of 15 children, 10 men, and 29 women. Six patients were excluded on account of inadequate data (four women and two children), leaving 48 available for assessment. Eighteen were prescribed oral penicillin, 14 were on tetracycline, and 16 took other antibiotics. Thirty-three $(69 \%)$ had a residuum of less than one day's supply and may be considered as compliant. Three $(6 \%)$ were left with more than two days' supply at a time when all should have been taken, and may be regarded as non-compliant ; the remaining $12(25 \%)$ occupied an intermediate position. Thus over twothirds of the group conformed to instructions and about onethird stopped prematurely or took their antibiotic in a desultory manner.

\section{Long-term Treatments}

Patients on long-term treatment were entered as they came to notice over a period of two years. It was important in calculating the compliance ratio of each patient that the period of assessment should be precisely determined, and the boundaries were therefore taken as the first and last prescription issued while the patient was under observation.

A total of 104 patients were potentially eligible for inclusion in this series; 46 of these were excluded because either their treatment was supervised by others or they had an option on dosage frequency; this left 58 for inclusion. Comparison of the age and sex structure of the excluded and included groups showed no significant difference. The mean age of the 58 patients was 57 years, and female patients were in excess $(43: 15)$. Thirty-two patients were married, 21 were widowed, and five were single. The mean length of observation was 326 days. Twenty-one were taking digoxin, 11 were on thyroxine, and 26 took a variety of drugs.

Nine characteristics were noted for each patient: sex, age, marital status, social isolation, social class, demography, ability of the diagnosis to arouse anxiety, dosage frequency, and the duration of observation.

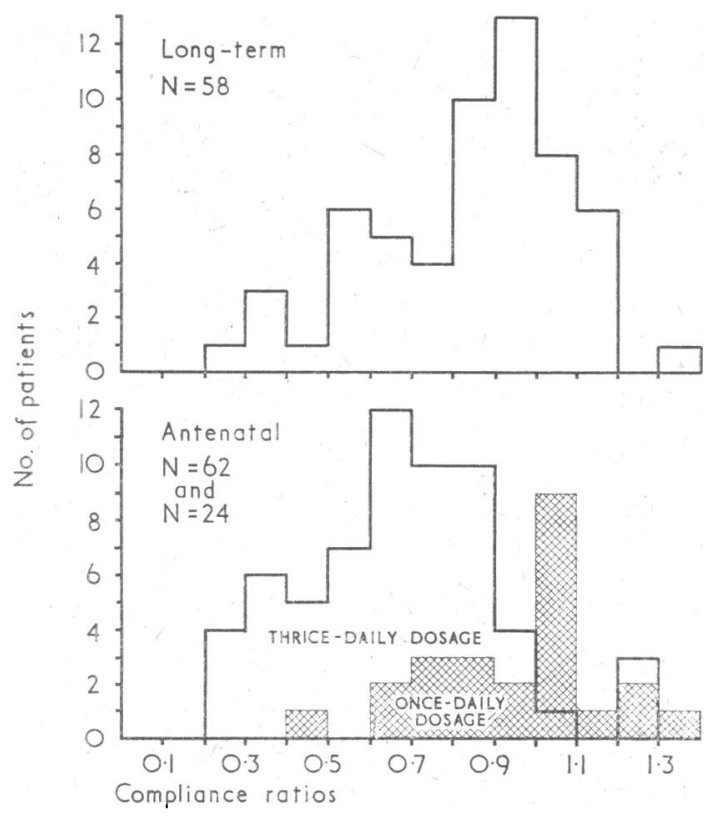

Distributions of the compliance ratios for long-term and antenatal patients.
The compliance ratio of the 58 patients had a mean of 0.84 and a standard deviation of 0.24 (see Chart).

A stepwise multiple regression of the nine variables on the compliance ratio (Porter, 1967) was calculated. None of the variables correlated with the compliance ratio, but social isolation, which made the greatest contribution to the regression $(38.7 \%)$, approached conventional significance $(P=0.1)$-that is, socially isolated patients tended to neglect their drugs. The next greatest contribution to the regression $(21.0 \%)$ was made by dosage: patients on a once-daily dosage tended to have a higher compliance ratio than those on divided dosages. Sex and age made no contribution whatsoever to the regression $(\mathrm{F}=0.0043$ and 0.0053 respectively).

\section{Antenatal Patients Taking Iron Tablets}

All pregnant women who presented for booking over a period of 16 months were considered for admission. Of the 76 original patients 14 were excluded, owing to divided responsibility for their care, leaving 62 for admission. Their mean age at booking was 25.7 years, and $19(31 \%)$ were primigravidae. The antenatal patients were observed for a shorter time (an average of 125 days) than those on long-term treatments ( 326 days); it follows that the results were more vulnerable to experimental error.

Haemoglobin estimations were made on two occasions; the range of timing of the first was 9 to 24 weeks (mode 12 weeks) and for the second 21 to 38 weeks (mode 32 weeks). It was not until the main study, using thrice-daily ferrous sulphate tablets, was completed that it was thought to be useful to continue with another series of mothers taking a once-daily preparation of iron (Ferro-Gradumet); it was hoped that information might be forthcoming about the relevance of dosage frequency.

Nine different traits were recorded for each patient: age, parity, past history, social class, demography, stage entered in weeks, duration of observation in days, whether the pregnancy was planned or unplanned, and the change of haemoglobin concentration expressed as milligrams per day. The compliance ratio was estimated by the method described earlier for long-term patients.

The compliance ratio of the 62 patients had a mean of 0.67 and a standard deviation of 0.24 (see Chart).

A stepwise multiple regression of the nine variables on the compliance ratio (Porter, 1967) was calculated. Duration, which was negatively correlated, was the first variable to enter the model and the regression was statistically significant $(\mathbf{P}=0.05)$. Duration accounted for $39.2 \%$ of the regression. After accounting for duration the variable which entered the model (parity) contributed $23.5 \%$ of the regression. If parity is considered in isolation it is significantly correlated to the compliance ratio $(P=0.05)$, but after accounting for the contribution of duration the correlation is not significant, thereason for this being some weak correlation between the two variables. Yet the two together-that is, duration plus parityhad a significant regression $(\mathbf{P}=0.05)$. Social class and intention contributed 11.8 and $9.7 \%$ respectively of the regression after accounting for duration and parity. Taken in isolation these two were not significantly correlated, but four traits (duration, parity, intention, and social class) taken together were significantly correlated $(P=0.05)$.

Compliance, therefore, was discouraged by a combination of long duration of observation, multiparity, a pregnancy which was planned, and manual social class.

Addition of further traits rendered the multiple regression not significant.

A stepwise regression of haemoglobin change on the different traits was done, in particular to determine the role of the compliance ratio (Porter, 1967). No significant correlation. was shown between the compliance ratio and change in haemo- 
globin. Duration of observation and social class, taken in isolation and in combination, were significantly correlated; a sparing of the usual haemoglobin fall was contributed by short duration of observation and non-manual social class.

The correlations in the antenatal and long-term series were examined for evidence of trends. Only two traits-demography and social class-were held in common and were suitable for comparison. On inspection demography was discarded, since it contributed only $5 \%$ to the regression of the antenatal variables on the compliance ratio. A trend may be discerned with social class. In both surveys manual social class tended to be associated with a low compliance ratio. This trait contributed $12.5 \%$ to the regression of the long-term patients and $11.8 \%$ to that of the antenatal patients.

Ferro-Gradumet was used in this investigation for inquiry into the relation between compliance and daily dosage. This second series of 24 patients was, unfortunately, sequential to the first, but did not differ significantly for any of the principal traits. The patients on Ferro-Gradumet proved to be very co-operative and had a mean compliance ratio of 0.94 , with a standard deviation of 0.21 (see Chart).

The various distributions of the compliance ratios of the three groups of patients studied (Chart and Table II) accord sufficiently with normality to permit the use of a $t$ test to compare the means.

TABLE II.-Comparison of Means of Compliance Ratios for Three

\begin{tabular}{|c|c|c|c|}
\hline & $\mathbf{N}$ & Mean & S.D. \\
\hline 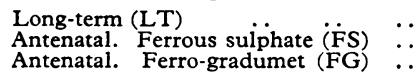 & $\begin{array}{l}58 \\
62 \\
24\end{array}$ & $\begin{array}{l}0.841 \\
0.671 \\
0.941\end{array}$ & $\begin{array}{l}0.237 \\
0.237 \\
0.214\end{array}$ \\
\hline
\end{tabular}

The mean compliance ratio of the antenatal patients taking Ferro-Gradumet tablets was significantly higher than in those taking ferrous sulphate tablets $(\mathrm{P}<0.001)$. The Ferro-Gradumet group were also more compliant than patients undergoing long-term maintenance treatment; the difference here approached conventional significance $(P=0.07)$.

\section{Discussion}

Nineteen out of 82 patients failed to reattend at some stage during the imipramine trial. This represents an overt defaulting rate of about one-quarter and is comparable to the median of the rates reported in 22 other published studies. The very low occult defaulting rate (about $3 \%$ ) compares most favourably with the range $(13-51 \%)$ reported in five studies of hospital outpatients (Joyce, 1962 ; Reynolds et al., 1965 ; Willcox et al., 1965 ; Maddock, 1967 ; E. D. Freis, personal communication, 1967). One must be cautious in comparing studies which vary widely in duration, method, and criteria, but it does seem that patients may conform to the instructions of their general practitioner more faithfully than to those issued by a doctor working with hospital outpatients. If this be true then the implications are far-reaching, for it would mean that the locus of drug trials would be best moved, whenever possible, away from hospital outpatient departments and into general practice.

Evidence from the five studies quoted above suggests a disturbingly high rate of occult defaulting from outpatient drug trials. This defaulting will remain undetected unless special methods of detection are used; it is surprising that of the hundreds of outpatient trials published up to now only three (Joyce, 1962 ; Berry et al., 1963 ; Scarpitti et al., 1964) have made use of a tablet marker.

The 54 patients in this study who took antibiotics proved to be reasonably compliant to instructions. None the less, there is evidence from other studies that compliance deteriorates rapidly beyond the fifth day of a course (Bergman and Werner, 1963 ; Charney et al., 1967) for reasons which Ben Jonson understood (Volpone: "No, no, no, I'm very well, You need prescribe no more"). This finding casts doubt on the usefulness of prolonged courses of penicillin in the treatment of streptococcal throat infections (American Heart Association, 1960).

The results for the long-term patients in the practice showed no evidence of widespread defaulting, and it seems that most of them found it easy to follow a regular routine. The finding that socially isolated patients tended to neglect their drugs is consistent with other studies (Hobson and Blackburn, 1953; Semmence, 1959 ; Parkes et al., 1962 ; Schwartz et al., 1962; Berry et al., 1963), and it is clear that such patients require careful supervision (Hughes, 1968). The failure of age to contribute to the regression is surprising, but is supported by the work of others (Stott, 1959 ; Schwartz et al., 1962 ; Richards, 1964 ; Maddock, 1967). It is also generally agreed that there is no sex difference in drug defaulting (Rigby, 1958 ; Stott, 1959 ; Luntz and Austin, 1960 ; Schwantz et al., 1962 ; Willcox et al., 1965; Maddock, 1967); but there is some contrary evidence (Dixon et al., 1957 ; Wynn-Williams and Arris, 1958 ; Tuberculosis Chemotherapy Centre, Madras, 1960).

The antenatal patients on thrice-daily iron tablets did not fare so well, taking only two out of three of their prescribed tablets. Defaulting was shown to be significantly correlated with a variety of traits. Although no distinct and recognizable archetype emerged, mothers of high parity and low socioeconomic group are particularly suspect. The importance of social class is suggested by other work ; better-educated patients persevere longer with psychotherapy (Imber et al., 1955 ; Frank et al., 1957 ; Cole et al., 1962) and drugs (Lipman et al., 1965). They also patronize immunization and cervical smear programmes more than patients in low socio-economic groups (Clausen et al., 1954; Francis et al., 1955 ; Deasy, 1956; Glasser, 1958 ; Merrill et al., 1958 ; Rosenstock et al., 1959 ; Cochrane, 1968).

The study failed to find any correlation between compliance and change in haemoglobin during pregnancy. The haemoglobin concentration usually falls during pregnancy because the proportional increase in plasma volume exceeds that of the erythrocyte mass (Dieckmann and Wegner, 1934). This fall may sometimes be avoided or checked by giving supplemental iron, and this suggests that the change is pathological rather than physiological. The alternative view, persuasively argued by Hytten and Duncan (1956), contends that an excess of iron artificially stimulates haemopoietic function and that the increase in haemoglobin concentration does not necessarily confer any benefit (Fowler and Barer, 1941 ; Lund, 1951 ; Paintin et al., 1966). Whichever view is correct there will exist a threshold of effective therapy or stimulus. Below the threshold the daily supplemental iron will not be sufficient to exert the maximum sparing on the haemoglobin levels; above the threshold excessive and useless iron is being administered. There is evidence that this threshold lies within the range 39-105 $\mathrm{mg}$. of elemental iron per day (Kerr and Davidson, 1958 ; De Leeuw et al., 1964 ; Paintin et al., 1966).

One tablet of ferrous sulphate contains $60 \mathrm{mg}$. of elemental iron; it is clear that a thrice-daily dosage will supply a considerable excess of iron and that a patient must be a gross defaulter to be deprived of the sparing effect. In this study only 4 out of 62 patients took less than one in three of their iron tablets, hence the failure to demonstrate a correlation between compliance and the maintenance of haemoglobin levels.

The co-operation of patients on a once-daily dosage of iron (Ferro-Gradumet) was significantly better than those taking a thrice-daily preparation (Chart, Table II). Supporting evidence for the advantages of a once-daily schedule is found in the model for patients having long-term treatment; though dosage did not correlate significantly with compliance, it none the less made a substantial contribution to the regression in a 
direction favouring once-daily dosages. Other work suggests that a once-daily dose schedule is adhered to more faithfully than a divided-dose schedule (Rose, 1941 ; Nugent et al., 1965; Oakley, 1967) and is more popular (Ziehm and Likos, 1966).

\section{Conclusion}

The risk of drug defaulting may be reduced by making every effort to ensure that all patients understand instructions and are supervised frequently. The number of different drugs prescribed should be reduced to a minimum and preference be given to preparations which need to be taken only once a day and which have few side-effects. Present evidence suggests that one should be particularly wary of the socially isolated patient and those of poor education.

There is a need for further studies; in particular for a study involving similar classes of patients from both a hospital and a general practice background. Only this can resolve the suspicion that patients may be more reliable in taking their drugs when treated by their own general practitioner.

Partial or complete failure to appreciate the problem is widespread. The consequences were slight while therapeutics was, in effect, mostly confined to placebo therapy. With the advent of specific treatments the consequences of poor co-operation became more serious, though much of the problem has been masked and mitigated by the wide range of effective dosage of most drugs. Defaulting during a drug trial must not be allowed to escape attention; if it passes unnoticed serious harm may be done to the conclusions reached.

It must be emphasized that it has not proved possible to Identify an uncooperative type. Every patient is a potential defaulter. Compliance can never be assumed.

I thank Professor W. W. Holland, Dr. R. Kelly, Professor M. Weatherall, Mr. E. Gaskell, Mr. H. Kasap, and Mr, I. Collier for their help and advice. I am indebted to 11 drug firms for their generous grants (Abbott Laboratories Ltd., Bayer Co., Beecham Ltd., Ciba Ltd., Eli Lilly \& Co. Ltd., Glaxo Ltd., John Wyeth and Brother Ltd, May and Baker Ltd., Smith Kline and French Ltd. Upjohn Ltd., and Vitamins Ltd.).

Tablets were kindly supplied by Abbott Laboratorites Ltd., Geigy Pharmaceutical Co. Ltd., Roche Products Ltd., and Vitamins Ltd.

\section{REFERENCES}

American Heart Association (1960). Circulation, 21, 151

Bergman, A. B., and Werner, R. J. (1963). New Engl. Ұ. Med., 268, 1334. Berry, D., Ross, A., and Deuschle, K. (1963). Amer. Rev. resp. Dis., 88,

Charney, E., et al. (1967). Pediatrics, 40, 188.

Clausen, J. A., Seidenfeld, M. A., and Deasy, L. C. (1954). Amer. צ. publ. Hith, 44, 1526.

Cochrane, A. L. (1968). Brit. med. Y., 1, 443.

Cole, N. J., Brauch, C. H. H., and Allison, R. B. (1962). Amer. ¥. Psychiat., 118, 1004 .

Corrigan, J. C., and Strauss,, M. B. (1936). 7. Amer. med. Ass., 106, 1088.

Curtis, E. B. (1961). Nursing Outlook, 9, 290.

Deasy, L. C. (1956). Amer. soclol. Rev., 21, 185.
De Leeuw, N. K. M. Lowenstein, L., and Hsieh, Y. S. (1964). Proceedings of $X$ Congress of the Society of Haematologists, p. 27. Quoted ings of $X$ Congress of the
by Paintin et al. (1966).

Dieckmann, W. J., and Wegner, C. R. (1934). Arch. intern. Med., 53, 71.

Diron, W. M., Stradling, P., and Wootton, I. D. P. (1957). Lancet, 2, 871.

Ellison, P. M. (1964). Lancet, 1, 389.

Ferobee, S. H. (1964). Lancet, 2, 147.

Fowler, W. M., and Barer, A. P. (1941). Amer. 7. med. Sci., 201, 642.

Frencis, T. et al. (1955). Amor. 7. publ. Hlth, 45, Suppl. p. 1.

Frank, J. D., Gliedman, L. H., Imber, S. D., Nash, E. H., and Stone, A. R. (1957). Arch. Neurol. Psychiat. (Ćhic.), 77, 283.

Freis, E. D. (1966). In Antihypertensive Therapy, edited by F. Gross. New York.

Glasser, M. A. (1958). Amer. 7. publ. Hlth, 48, 141.

Habson, W., and Blackburn, E. K. (1953). Brit. med. F., 1, 647

Hughes, W. (1968). Lancet, 1, 747.

Hytten, F. E., and Duncan, D. L. (1956). Nutr. Abstr. Rev., 26, 855.

Imber, S. D., Nash, E. H., and Stone, A. R. (1955). J. clin. Psychol., 11, 281 .

Joyce, C. R. B. (1961). Ann. rheum. Dis., 20, 78

Jopce, C. R. B. (1962). \%. chron. Dis., 15, 1025.

Kerr, D. N. S., and Davidson, S. (1958). Lancet, 2, 483.

Kuhn, R., György, P., and Wagner-Jauregg, T. (1933). Ber. dtsch. chem. Ges., 66, 317 .

Lipman, R. S., Rickels, K., Uhlenhuth, E. H., Park, L. C., and Fisher, S. (1965). Brit. F. Psychiat., 111, 1043.

Land, C. J. (1951). Amer. F. Obstet. Gynec., 62, 947.

Luntz, G. R. W. N., and Austin, R. (1960). Brt. med. F., 1, 1679.

Maddock, R. K. (1967). Y. Amer. med. Ass., 199, 169.

Malahy, B. (1966). Amer. F. hosp. Pharm., 23, 282.

Merrill, M. H., Hollister, A. C., Gibbens, S. F., and Haynes, A. W. (1958). Amor. 7. publ. Hlth, 48, 146.

Nugent, C. A., Ward, J., MacDiarmid, W. D., McCall, J. C., Baukol, J., and Tyler, F. H. (1965). F. chron. Dis., 18, 323.

Oakley, W. G. (1967). G.P. (Kansas), February 1967, p. 4.

Paintin, D. B., Thomson, A. M., and Hytten, F. E. (1966). 7. Obstet. Gynaec. Brit. Crolth, 73, 181 .

Park, L. C., and Lipman, R. S (1964). Psychopharmacologia (Berl.), 6, 299.

Parkes, C. M., Brown, G. W., and Monck, E. M. (1962). Brit. med. F., $1,972$.

Porter, A. M. W. (1966). Brit. med. 7., 1, 1301.

Porter, A M. W. (1967). M.D. Thesis. The Problem of the SelfAdministration of Drugs, University of London.

Reaton, C. A., Affleck, J. W. Carstairs, G. M., and Forrest, A. D. (1963). Acta psychiat. scand., 39, 548 .

Reynolds, E., Joyce, C. R. B., Swift, J. L., Tooley, P. H., and Weatherall, M. (1965). Brit. 7. Psychiat., 111, 84.

Richards, A. D. (1964). Brit. F. Psychiat., 110, 46.

Richter, D. (1961). Neuro-Psychopharm., 2, 421.

Rigby, J. P. V. (1958). Tubercle (Lond.), 39, 336.

Robinson, F. A. (1951). The Vitamin B Complex, p. 159. New York.

Rooe (1941). Dtsch. med. Wschr., 67, 1306. Quoted in Trop. Dis. Bull., $1942,39,396$.

Rooenstock, I. M., Derryberry, M., and Carriger, B. K. (1959). Publ. Hlth Rep. (Wash), 74, 98.

St. Bartholomew's Hospital (1964). Lancet, 2, 639.

Scarpitti, F. R., Lefton, M., Dinitz, S., and Pasamanick, B. (1964). Arch. gex. Psychiat., 10, 143.

Schwartz, D. (1965). Geriatrics, 20, 517.

Schwartz, D. Wang, M., Zeitz, L., and Goss, M. E. W. (1962). Amer. 7. publ. Hlth, 52, 2018.

Semmence, A. (1959). Brit. med. 7., 2, 1153

Swoet, H. (1959). Bull. int. Un. Tuberc., 29, 285.

Tuberculosis Chemotherapy Centre, Madras (1960). Bull. Wld Hlth Org. 23, 535.

Willcox, D. R. C., Gillan, R., and Hare, E. H. (1965). Brit. med. 7., 2, 790.

Wynn-Williams, N., and Arris, M. (1958). Tubercle (Lond.), 39, 138.

Ziehm, D. J., and Likos, J. (1966). Obstet. and Gynec., 28, 430. 